\title{
Difference of Motive and Coping Strategy between Anger and Sadness*
}

\author{
Nak-Hwan CHOI ${ }^{1}$
}

Received: April 21, 2020. Revised: May 30, 2020. Accepted: June 05, 2020

\begin{abstract}
Purpose: Current study aimed at exploring the effects of ambient anger versus sadness on motive type and coping strategy type when consumers make decision. It focused on whether the negative affects of the anger and the sadness differentially induce approach versus avoidance motive at the place of making decision, and also explored the coping strategy differences between the consumers under the anger and those under the sadness, that is, which strategy is more used between problem-focused strategy and affect-focused strategy when they are under each negative affect. Research design, data and methodology: The experimental groups were divided into two types of group such as the anger-felt group and the sadness-felt group. The experiment was performed with the between-subjects design based on the anger and the sadness. Questionnaire data were collected from undergraduate students assigned to each of the anger group and the sadness group operated by the scenario method, and the data were used to verify research hypotheses by t-test. Results: - First, the anger induced the approach motive more rather than the avoidance motive in making decision. Second, to cope the negative affects, consumers under the anger used problem-focused strategy more than affect-focused strategy, while those under the sadness used affectfocused strategy more than problem-focused strategy. Therefore, this article contributes to the theory related to motive and making decision taken place to consumers under ambient negative emotions. Conclusions: Focusing on the results of this study, there could be managerial implications to brand or product marketing managers. Checking which affect consumers previously felt between anger and sadness when they are under negative affects is at issue to the brand or product marketers when they appeal their brand or product to the consumers. The marketers should build and communicate the messages about their product or brand in the respect of the points of showing problem solution or the best way to handle things to appeal the consumers under the anger. And they should develop and communicate the messages about their product or brand emphasizing the aspects of letting consumers' sad feelings out somehow or controlling their emotions to the consumers under sadness.
\end{abstract}

Keywords : Anger, Coping Strategy, Motive, Sadness

JEL Classification Code: C83, L81, M31, P46.

\section{1. 서론}

하나의 상황에서 느낀 감정은 관련이 없는 다음의 의사결정에 영향을 미치는 환경(incidental) 감정 이 될 수 있다. 평가경향이론 (appraisal

* This research was supported by "Research Base Construction Fund Support Program" funded by Jeonbuk National University in 2020.

1 Professor, Department of Business Administration, Jeonbuk National University, Korea. Email: cnh@jbnu.ac.kr

(c) Copyright: The Author(s)

This is an Open Access article distributed under the terms of the Creative Commons Attribution Non-Commercial License (http://Creativecommons.org/licenses/by-nc/4.0/)

which permits unrestricted noncommercial use, distribution, and reproduction in any medium, provided the original work is properly cited. tendency framework)은 감정의 강도와 감정을 유발한 주제(appraisal theme)에 따라서 서로 다른 동기가 유발되어(Lemer \& Keltner, 2000), 감정을 유발한 문제가 해결될 때까지 다음의 판단과 의사결정에 영향을 미치는 목적지향적 과정으로서 평가경향을 설명한다. 감정을 느끼게 하는 원인요인에 따라서 느끼는 감정이 달라지고, 느껴지는 감정은 그 감정을 느끼게 했다고 생각되는 중요한 원인요인과 관련하여 미래의 사건의 평가에서 특정한 인지성향을 촉진하고 다음의 문제나 기회를 신속하게 처리하게 하는 역할을 한다(Han, Lemer \& Keltner, 2007).

이 연구는 접근목적의 달성에 실패하여 느끼는 화(anger)와 슬픔 (sadness)에 관한 연구이다. 화는 개인이 통제가 가능한 타인의 잘못으로 실패가 발생했다고 판단하는 경우에 느껴지는 부정감정이고(Lemer, Li, Valdesolo \& Kassam, 2015), 슬픔은 개인이 통제할 수 없는 환경에 의해 
실패가 발생했다고 판단하는 경우에 느겨지는 부정감정이다(Lazanus, 1991). 따라서 접근목적의 추구에서 실패가 확실한 경우에, 실패의 원인이 통제가 가능한 타인의 잘못으로 지각되면 화감정을 느끼고, 실패의 원인이 통제가 불가능한 환경에 있다고 판단하는 하면 슬픔을 느끼게 되어, 화와 슬픔 간에 원인주제가 다르다. 따라서 화와 슬픔을 느낀 소비자 간에 차후의 의사결정에서 동기와 주의하는 초점이 서로 다를 수 있다.

Tomkins(1978)는 동기는 구체적인 목적 메카니즘이고 상대적으로 숙고되는 측면이 있고, 감정은 일반적인 목적 메카니즘이고 상대적으로 충동적인 측면이 있음을 간파하였으며, 감정이 동기를 선행할 수 있다고 하였다. 따라서 감정이 행동의 방향을 결정하고 활성화시키는 선행역할을 할 수 있음을 알 수 있다. 그런데 강한 슬픔은 식욕, 성욕, 사회화 욕구의 감퇴, 과거에 수행해온 행동에 대한 관심의 약화를 가져올 수 있어서(American Psychiatic Association, 2000), 회피적 행동성향을 유도할 수 있다. 반면에 화는 접근적 행동성향을 활성화 시키고(Plutchik, 1980), 격앙된 무례한 공격을 유도할 수 있다(Blanchard \& Blanchard, 1984; Lewis, 1993). 이러한 기존의 연구는 화와 슬픔 간에 소비자가 지향하는 동기가 서로 다를 수 있음을 추론하게 한다.

감정에 관한 선행연구(Schwarz, 1990) 에서, 감정은 의사결정과 관련된 정보처리의 깊이에 영향을 미치고, 상황에 좀 더 많은 주의를 하게하여 소비자가 적응적 역할을 하게 할 수 있음을 탐색하였다. 하지만, 부정감정에서 체계적 처리는 부정감정의 상태에 몰입되어 부정 감정이 지속되게 할 수 있는데, 슬픔을 느낀 소비자가 신중하게 정보를 처리하는 경우에 슬픔감정이 지속되어 판단에 슬픔감정이 영향을 미쳐서 정확성이 감소될 수 있다(Ambady \& Gray, 2002). 그리고 부정적인 감정 상태에 있는 사람은 정보원의 전문성, 매력성, 선호성과 같은 휴리스틱(heunistic) 단서에 영향을 적게 받고, 판단에서 자신의 상투성(stereotypes)에 더 의존하는 경향이 있다(Bodenhausen, Gabriel, \& Linenberger, 2000). 화가 난 소비자는 의사결정에서 상투적 판단과 휴리스틱 단서에 의존하고, 정보를 체계적으로 처리하기 보다는 자신의 입장에 대한 긍정적인 정보를 유지하려 한다Clore, Wyer, Dienes, Gasper, Ghom, \& isbell, 2001).

그런데, 화가 난 소비자와 슬픔을 느낀 소비자가 모두 좀 더 경계적이고 체계적인 정보처리를 하는가? 아니면 자신의 상투성에 더 의존하여 정보를 처리하는가? 화가 난 소비자와 슬픔을 느끼는 소비자는 어떤 동기를 가질까? 화가 난 소비자는 타인의 잘못을 자신이 통제가능하다고 판단하고 자신의 긍정적인 입장을 고수하여, 차후의 의사결정에서 득을 얻을 수 있는 접근동기를 가질 수 있다. 그런데 슬픔을 느낀 소비자는 차후의 의사결정에서 환경의 통제가 불가능할 수 있다고 판단하여 손실을 회피하려는 회피동기를 가질 수 있다. 그런데 선행연구에서 화와 슬픔 간의 동기의 차이에 대한 연구는 찾아보기 어렵다.
한편, Atalay and Meloy(2011)는 소비자가 소매점포 매장에서 쇼핑행동을 하여 위협받는 자아에서 자신의 주의를 분산시키는 경향이 있음을 탐색하였고, Comil and Chandon(2013)은, 자기의 지역 스포츠 팀이 경기에서 지고 난 후에 소비자가 부정감정을 느끼고 경기와 관련이 없는 지방이 풍부한 고칼로리의 달콤한 음식을 소비하는 성향을 관찰하였다. 소비자가 자신이 통제할 수 없는 원인에 의한 지역 팀의 패배에서 경기와 관계가 없는 소비행동을 함을 관찰하였다. 이러한 성향에서 소비자가 통제할 수 없는 원인에 의해서 접근목적의 달성에 실패하여 슬픔을 느끼는 경우에 슬픔을 달래려고 슬픔감정에 초점을 두고 슬픔에서 탈출하려는 행동을 함을 추론할 수 있다. 즉 슬픔을 느끼는 소비자는 부정 감정인 슬픔에 초점을 두고 슬픔을 극복할 수 있는 전략을 수립하고 집행할 수 있다. 그런데 통제가 가능한 타인의 잘못에 의해 접근목적을 달성하지 못하고 실패하여 화가 난 소비자는 자신이 타인의 잘못을 통제할 수 있다고 보기 때문에, 그 타인과 자신을 분리하여 타인과의 동일시에서 이탈하여 자신의 긍정적인 입장을 고수하고, 타인의 잘못 또는 그 잘못에 대한 자신의 통제성문제에 초점을 둔 전략을 수립하고 집행할 수 있다. 즉 슬픔을 느낀 소비자와 화를 느낀 소비자 간에 극복전략에서 초점이 서로 다를 수 있다. 그런데 선행연구에서 화와 슬픔 간의 주의의 초점차이에 대한 연구는 찾아보기 어렵다.

따라서 이 연구는 화와 슬픔 간의 동기와 주의의 초점차이에 대한 연구를 하고 관리적 시사점을 도출하기 위해, 연구의 목적을 설정한다. 첫째, 환경감정으로서 화감정과 슬픔감정의 차이를 이론적으로 고찰한다. 둘째, 동기의 유형을 접근동기와 회피동기로 나누어 이론적으로 고찰한다. 셋째, 화감정과 슬픔감정 간에 유도되는 동기의 차이를 탐색하고, 극복전략에서 초점의 차이를 식별한다.

따라서 이 연구에서 탐색된 환경감정으로서 화와 슬픔 간의 동기의 차이와 주의의 초점차이는 감정 이론의 발전에 기여할 수 있고, 마케터에게 화가 난 소비자와 슬픔을 느낀 소비자 간에 소구방법의 차별점을 시사점으로 제시할 수 있다.

\section{2. 이론적 배경과 가설의 설정}

\section{1. 접근동기와 회피동기}

접근동기는 긍정적 자극을 향한 행동을 유도하고 촉진하는 동기이고, 회피동기는 부정적 자극으로부터 이탈하는 행동을 유도하고 촉진하는 동기이다(Elliot, 2008). 동기의 웰빙효과(well-being effect5)는 동기목적 추구의 과정과 관련된 행동이론(activities theor)과 성과와 관련된 목적이론(telic theory)으로 설명된다(Diener, 1984). 목적 추구의 성과가 웰빙을 결정한다는 목적이론은, 접근목적의 추구에서 성공과 실패가 
회피목적의 추구에서 성공 및 실패와 서로 다른 결과를 초래하고, 서로 다른 감정을 체험하게 하여, 접근목적과 회피목적은 웰빙에 서로 다른 의미가 있다고 본다. 촉진적 접근과 방어적 회피의 동기시스템은 사전에 서로 다른 감정을 체험하게 하는데(Lang, 1995), 접근동기는 흥분 의기양양 등의 감정을 느끼게 하고, 회피동기는 근심 공포 등의 감정을 느끼게 할 수 있다(Carver, 2008). 그리고 목적추구의 결과에 따라 느끼는 감정이 달라질 수 있다. 접근목적의 추구에서 긍정적인 성과는 흥분감을 느끼게 하지만, 부정적인 결과는 화 또는 슬픔을 느끼게 할 수 있다. 그리고 회피목적의 추구에서 무사고의 성과는 안도감(calmness)을 느끼게 하지만, 사고가 발생된 결과는 동요감(agitation)을 느끼게 할 수 있다.

소비자는 자신에게 바람직한 목적을 더욱 추구하는데, 목적의 바람직성은 소비자의 초점에 의해서 결정된다. 소비자가 유쾌함을 느끼는 정도에 초점을 두면, 목적의 바람직성은 목적달성에서 유쾌감을 느끼는 정도에 의해서 결정되고, 유쾌한 감정을 느끼는 빈도에 의해 웰빙을 더 지각할 수 있다(Updegraff, Gaable, \& Taylor, 2004). 자신의 자아에 대한 의미 또는 가치에 초점을 두면 목적의 바람직성은 목적이 자신의 진정한 자아(true seff)와 일치한다고 생각하는 정도에 의해서 결정된다(Ryan \& Deci, 2000).

한편 목적 추구의 과정이 웰빙을 결정한다는 행동이론은 접근목적과 회피목적의 추구과정이 실질적으로 서로 달라서 접근목적과 회피목적은 웰빙에 서로 다른 의미가 있다고 본다. 접근목적의 추구과정은 이상적 상태와 현재의 상태 간의 격차를 감소시키는 과정이고, 회피목적의 추구과정은 바람직하지 못한 상태와 현재 상태 간의 격차를 크게 하는 과정이다(Carver \& Scheier, 1998). 그런데 접근목적의 추구과정이 회피목적의 추구과정 보다 가시적이고 모니터가 용이하여, 좀 더 잘 관리될 수 있어서(Higgins, 1997), 접근목적의 추구가 회피목적의 추구 보다 웰빙을 촉진할 가능성이 크다.

그런데 추구하는 목적의 자아부합성은 웰빙에 효과가 있지만, 목적달성과정의 실행가능성 (feasibility) 또는 실행에서 자기효능감(self efficacy)과 관계가 없다. 목적의 바람직성과 목적달성과정의 실행성은 서로 다른 개념이다. 소비목적의 바람직성이 소비자에 따라서 서로 다르게 지각될 수 있는 것처럼, 목적달성과정의 실행가능성도 서로 다르게 지각될 수 있지만, 실행가능성은 추구하는 목적을 향한 행동의 수행능력에 대한 판단과 행동이 목적달성에 성공적이다는 신념에 의해서 결정되고(Bandura, 1977; Oettingen \& Gollwiter, 2004), 과거에 목적을 추구해본 경험과 내재적인 재능에 기초하여 지각된다.

목적의 실행가능성은 경험하는 감정에 영향을 주고, 웰빙에 영향을 미친다. 회피동기의 소비자가 접근동기의 소비자 보다 접근목적의 성공적인 실현에서 행복감을 덜 느끼고, 성공을 하지 못하는 경우에 슬픔을 덜 느낀다. 반면에 그들은 회피목적의 성공적 수행에서 안도감을 더욱 느끼고 성공하지 못하는 경우에 더 근심을 하게 된다IIdson,
Liberman, \& Higgins, 2000). 접근동기 수준이 높은 소비자에게 접근 목적은 좀 더 바람직하고 실현가능성이 크고, 회피동기 수준이 높은 소비자에게 회피목적이 좀 더 바람직하고 실현가능성이 크다. 따라서 접근지향적 소비자는 접근목적의 바람직성과 실현가능성 때문에 접근목적에서 혜택을 더욱 얻을 수 있고, 웰빙을 지각할 수 있다. 회피지향적 소비자는 회피목적이 더 바람직하고 실현가능하여 회피목적의 추구에서 더 혜택을 얻을 수 있고 웰빙을 지각할 수 있다.

그런데 소비자가 느끼는 특정의 감정은 특정의 위협이나 보상의 가능성 정보에 대한 주의를 유도하고(Tamir \& Robinson, 2007), 접근이나 회피 행동을 지원하는 생리적 반응을 유발하여(Frida, 1988), 소비자가 목적을 효과적으로 추구하게 할 수 있다(Carver, 2001). 이 연구는 화감정과 슬픔감정을 비교하여 동기와 초점의 차이를 연구한다. 따라서 소비자가 사전에 느끼는 화와 슬픔을 탐색한다.

\section{2. 화감정과 슬픔감정}

화감정은 자신의 성과에 긍정적으로 작용하는 강화요인이 배제되거나 종료되는 경우에 느낄 수 있고(Rolls, 1999), 목적의 달성이 개인적으로 중요한 경우에 통제가 가능한 주변상황이 목적의 달성에 부정적으로 작용하여 실패하면 느낄 수 있다(Lazalus, 1991). 여기서, 목적은 의식적으로 추구되는 목적과 함께 기초욕구(basic needs)를 포함하여 광범위하게 정의된다. 화감정을 유도하는 필요조건은 타인 또는 어떤 것이 목적의 달성에 부정적인 상황을 만들었다고 평가하여 유도되는 타인에 대한 비난(other-blame)인데, 자신에게 불리한 부정적인 사건 자체가 잘못된 것이고 불공평하며 적절하지 못하다고 판단하는 경우에도 화감정을 더욱 느낄 수 있다(Roseman, 1991). 따라서 사전에 조정하여 부정적인 상황을 예방할 수 있었다고 생각할수록 화감정을 더욱 느낄 수 있다.

한편 접근동기는 성공, 보상, 성취 등의 긍정적인 성과를 지향하는 방향으로 행동을 규제하여, 소비자가 긍정적인 성과에 초점을 두고 바람직한 최종 상태를 지향하는 접근동기시스템을 활성화 한다(Higgins, 2000). 일반적인 목적의 성취를 위한 특정 행동의 선택도 사전에 느낀 구체적인 감정의 유형에 따라 달라질 수 있다. 감정적 동기에서 감정과 관련된 목적을 향한 행동의 선택은 제약되고 선택의 반응시간은 짧아진다(Roseman, Wiest \& Swart, 1994). 감정적 행동에서 선택할 수 있는 행동대체안의 수가 제약되어 작아지고 선택적 반응의 시간적 간격이 축소된다. 즉 감정 시스템은 감정에 맞는 행동을 좀 더 신속하게 선택하여 빠른 행동을 하게한다. 따라서 타인의 잘못으로 성취목적의 달성이 좌절되어 화가 난 사람은 타인의 승인을 얻고 친구 관계를 유지하는 것과 같은 구체적인 동기적 목적 대신에, 불특정의 타인을 해치는 행동을 하는 성향과 같은 좀 더 일반적인 동기적 목적을 수용할 수 있다. 
화감정은 접근적 행동성향을 활성화 시키는 감정이다(Plutchik, 1980). 공격성향에 관한 과거 연구는, 무례한 공격은 부정적인 상황에서 탈출하려는 시도가 없어도 수행하는 공격성향으로 화감정과 관련되고, 방어적 공격은 부정적인 상황에서 탈출을 시도하는데 탈출이 불가능한 경우에 공격을 하는 성향으로 공포와 관계가 있다. 무례한 공격은 목적의 성취를 향한 접근적 행동인데, 화감정은 격앙된 무례한 공격을 유도하고 의사결정에서 접근행동을 촉진할 수 있다(Blanchard \& Blanchard, 1984; Lewis, 1993).

그리고 개개인이 성과에 어떻게 접근하는가는 성과를 통제할 수 있다는 기대와 성과의 중요성에 따라 달라진다. 개개인이 중요한 성과를 통제할 수 있다고 기대했는데 성과를 통제할 수 없는 것으로 판단되면 심리적으로 반항을 하게 된다. 사전에 통제할 수 있다고 기대했는데, 통제할 수 없다는 판단을 하면, 반항을 하고 통제성을 확보하려는 동기를 갖게 된다. 그러나 통제할 수 없는 성과에 여러 번 노출이 되면 개개인은 성과를 통제할 수 없다고 판단하고 목표에 접근하려는 동기 수준이 낮아지게 된다. 반항은 사전에 통제할 수 있다고 기대하는 개개인에게 외부에 도움이 없음을 신호 하는 행위이다. 화가 난 사람은 자신의 자아를 보호하고 육체적인 강인함 용감함 등의 성향을 보이며 접근동기를 갖는다. 화감정은 공격적이고 경쟁적으로 만들면 낙관적인 기대를 갖게 한다. 화감정과 낙관주의 간에 심리적 연결은 화감정이 접근동기를 갖게 유도한다. 즉 화감정은 접근동기에 개입하게 하여 낙관적 기대를 유도하고 낙관적 성향을 만들어 낸다(Lemer \& Kettner, 2001).

소비자가 바람직한 상태에 도달할 수 있는 능력을 갖고 있다고 믿거나 환경이 자신의 행동에 우호적으로 작용할 수 있도록 통제할 수 있다고 믿는 경우에 접근동기가 유발되어(Duhachek, Agrawal, \& Han, 2012), 화감정은 공격적이고 목적을 향한 경쟁심을 자극하여 회피 보다 접근 동기를 유도할 것이다.

한편, 성과에 대한 맥락의 영향에 대한 분석은 느겨지는 서로 다른 감정들 간의 차이점과 유사점을 발견 하게 한다. 소비자가 접근목적의 추구에서 중대한 손실이 발생했을 때, 사전에 대처하고 행동을 조절하여 부정적인 손실 상황을 예방하기가 어렵거나 또는 불가능했다고 생각하는 경우에 소비자는 슬픔을 경험할 수 있다. 손실을 발생시킨 환경에 대한 통제력이 없다고 판단되는 경우에 손실이 통제할 수 없는 환경에 기인하였다고 생각하여 슬픔을 느끼게 된다(Lazans, 1991). 그런데 소비자가 바람직한 성과를 창출할 수 있는 능력이 없다고 믿거나 환경이 자신의 행동에 우호적으로 작용하지 않는다고 믿는 경우에 회피동기가 유발된다(Duhachek, Agrawal, \& Han, 2012). 따라서 슬픔은 화처럼 접근목적의 추구에서 손실이 발생했을 때 느겨지지만, 통제할 수 없는 환경에서 탈출하려는 성향, 즉 회피동기를 유도할 수 있다.
슬픔을 느끼는 소비자는 현재 소유하고 있는 것을 제거하고 새로운 것을 구매 하려 하는데 이것은 환경을 변화시키고 싶은 욕망, 즉 기존의 나쁜 환경을 회피하려는 동기에서 유도된다. 슬픔을 느끼는 소비자는 자신의 소유물에 대한 판매 가격을 낮추고 새로운 것의 구매에서 높은 가격을 지불하면서 구매 하려는 성향을 보여 소유효과 (endowment effect)와 반대되는 성향을 보인다(Lemer, Small, \& Loewenstein, 2004). 그리고 접근목적의 추구에서 손실이 발생하여 유발되는 부정적인 자아격차에 대한 숙고는 부정적인 손실결과에서 소비자가 느끼는 부정적인 감정이 지속되게 한다(Lisjak, Bonezi, Kim, \& Rucker, 2015). 소비자는 부정적인 결과에서 탈출하여 고통을 회피하고 기쁨을 추구하는 성향이 있다(Higgins, 1997). 따라서 소비자는 환경이 자신에게 우호적으로 작용하도록 통제할 수 없다고 생각하여 슬픔을 느낀 소비자는 의사결정에서 그 환경을 향한 접근 보다 그 환경에서 회피하여 탈출하려 할 것이다.

H1: 화감정과 슬픔감정 간에 회피동기 수준과 접근동기 수준은 서로 다를 것이다.

H1a: 화감정은 회피동기 보다 접근동기를 유도할 것이다.

H1b: 슬픔감정은 접근동기 보다 회피동기를 유도할 것이다.

\section{3. 극복전략}

부정적인 기분은 위협을 지각하게 하고 좀 더 경계적이고 체계적인 처리를 하게 하여, 소비자는 느끼는 스트레스를 감소시키기 위한 인지적 행동적 극복전략을 사용할 수 있다. 이러한 스트레스의 극복전략은 스트레스를 유발한 원인, 즉 문제에 초점을 둔 극복전략과 스트레스를 유발한 원인에 대한 감정적 반응을 규제하는 감정에 초점을 둔 극복전략이 있다(Lazanus \& Folkman, 1984). 문제에 초점을 둔 극복 전략은 위협하는 상황을 개선할 수 있는 대안이나 방법을 생각하고 좀 더 나은 성과를 얻기 위해 스트레스를 유발하는 원인을 조정하는 전략이다. 그런데 감정에 초점을 둔 극복 전략은 스트레스를 유발한 상황에 대한 생각을 회피하고, 위협 그 자체를 재해석하여 부정적인 스트레스 감정을 직접적으로 규제하려는 전략이다. 즉 문제의 초점을 둔 극복 전략은 위협의 원인을 직접적으로 관리하는 전략이고, 감정에 초점을 둔 극복 전략은 위협에 대한 감정적 반응을 규제하는데 초점을 둔 전략이다(Duhachek \& Iacobucci, 2005). 소비자가 두 가지 극복전략 중에 어떤 전략을 선택하느냐는 자신을 위협하고 스트레스를 유발 하는 상황과 스트레스를 관리할 수 있는 자신의 능력을 어떻게 평가하는가에 영향을 받는다. 소비자가 그 위협을 제거시킬 수 있는 능력을 갖고 있다고 믿는 경우에, 문제에 초점을 둔 극복 전략을 좀 더 사용하고, 능력이 부족하거나 없다고 생각하는 소비자는 감정적 반응을 규제하는 
감정에 초점을 둔 전략을 더 사용할 수 있다(Sujan, Sujan, Bettman, \& Verhallen, 1999).

화감정은 자신이 통제 가능한 타인 또는 어떤 것이 부정적인 상황을 만들어 자신의 접근목적이 실패했다는 평가에서 느낀다. 화가 난 소비자는 부정적인 사건 자체가 불공평하며 잘못된 것이고 적절하지 못하다고 판단하며 자신에 대한 긍정적인 입장을 고수하려 한다(Roseman, 1991). 화에는 상황을 조정하고 관리하여 위협요인을 제거시킬 수 있는 능력이 자신에게 있다는 생각이 포함되어 있다. 사전에 자신이 부정적인 상황을 조정하여 예방할 수 있었다고 생각할수록 화감정을 더욱 느낄 수 있다. 따라서 화감정을 느끼는 소비자는 의사결정에서 문제에 초점을 둔 극복전략을 선택할 것이다.

그런데, 접근목적의 추구에서 사전에 대처하고 행동을 조절하여 중대한 부정적인 손실이 발생하는 상황의 예방이 불가능했다고 생각하는 경우에 슬픔감정이 느껴진다. 손실을 발생시킨 환경에 대한 통제력이 없고 손실이 통제할 수 없는 환경에 기인하였다고 판단하면, 소비자는 슬픔을 느끼게 된다(Lazanus, 1991). 따라서 접근목적의 실패에서 자신의 행동을 관리하여 성과를 창출할 수 있는 능력이 없고 통제가 불가능한 환경이 우호적으로 작용하지 않았다고 판단하여 슬픔을 느낀 소비자는 의사결정에서 통제가 불가능한 위협적인 원인에 초점을 두기보다 감정을 규제하기 위해 감정에 초점을 둔 극복전략을 선택할 것이다.

H2: 화감정과 슬픔감정 간에 극복전략에서 감정과 문제에 초점을 두는 정도가 서로 다를 것이다.

H2a: 화감정은 감정 보다 문제에 초점을 둔 극복전략을 선택하게 한다.

H2b: 슬픔감정은 문제 보다 감정에 초점을 둔 극복전략을 선택하게 한다.

\section{3. 실증방법과 자료수집}

\section{1. 화와 슬픔을 유도하는 시나리오 개발}

\subsection{1 화를 느끼게 하는 시나리오 개발}

실패가 개인이 통제가 가능한 타인의 잘못으로 발생했다고 판단하는 경우에 느껴지는 부정감정이 화이기 때문에(Lemer, Li, Valdesolo, \& Kassam, 2015), 개인적으로 중요한 목적이 자신에 의해 통제가 가능한 주변상황이 부정적으로 작용하여 실패하는 경우를 시나리오로 개발하고 화감정을 느끼게 유도한다.
나는 대학교에 입학하자마자 x공기업 입사하기 위해 학점관리는 물론 토익공부도 열심히 했다. 또한 자기개발 프로그램에도 적극적으로 참여하였고, 처공기업에서 요구하는 자격증도 미리 취득하였다. 그리고 **공기업'의 공채에 학점과 토익 성적표, 자격증, 기타의 활동내역서류를 제출하고 응시하여 1 차에서 통과했다. 드디어 오늘 2 차 면접시험을 보러 가는 중이다. 나는 면접 장소까지 운전을 하고 가야하기 때문에 아침에 일찍 출발했다. 혹시 모를 사고를 예방하기 위해 안전 속도를 유지하면서 목적지로 가고 있었다.

그런데 갑자기 옆에서 운전하던 차가 무리하게 끼어들기를 시도하였다. 나는 놀라서 경종을 울리며 주의를 주었다. 그러나 무리하게 운전하던 차는 급하게 브레이크를 밦으면서 끼어들었고, 나는 피하려고 노력했지만 지나가던 시내버스와 충돌하고 말았다. 거리는 아수라장이 되었고, 나는 사고를 내고 말았다. 무리하게 끼어들기를 한 운전자는 무면허였고, 나는 그렇게 고대했던 *ㅓ공기업 면접에 갈 수 없는 상황이 되었다. 면접시간에 늦을 수밖에 없었다. 혹여 지금 가더라도 면접시간에 늦을 수밖에 없었다.

사실 나는 이번 시험을 위해 최선을 다했고, 모두들 이번에 꼭 합격할 수 있을 거라며 나를 응원했다. 그런데..지금 나는 면접에 갈 수 없는 상황이 된 것이다. 나는 너무 화가 났다

\subsection{2. 슬픔을 느끼게 하는 시나리오 개발}

실패가 개인이 통제할 수 없는 환경에 의해 발생했다고 판단하는 경우에 느껴지는 부정감정이 슬픔이기 때문에(Lazanus, 1991), 자신에 의한 통제가 불가능한 주변상황이 부정적으로 작용하여 중요한 개인적 목적이 좌절되는 경우를 시나리오로 개발하고 슬픔감정을 느끼게 유도하였다.

나는 대학교에 입학하자마자 촉ㄱㄱ기업 입사하기 위해 학점관리는 물론 토익공부도 열심히 했다. 또한 자기개발 프로그램에도 적극적으로 참여하였고, x공기업에서 요구하는 자격증도 미리 취득하였다. 그리고 *ㅗ공기업의 공채에 학점과 토익 성적표, 자격증, 기타의 활동내역서류를 제출하고 응시하여 1 차에서 통과했다. 드디어 오늘 2 차 면접시험을 보러 가는 중이다. 나는 면접 장소까지 운전을 하고 가야 하기 때문에 아침에 일찍 출발했다. 혹시 모를 사고를 예방하기 위해 안전 속도를 유지하면서 목적지로 가고 있었다. 그런데 갑자기 전화벨을 울렸다. 나는 스피커폰으로 전화를 받았다. 경찰이었다. 사고가 났는데... 한 여자 분이 의식이 없이 넘어져 있고, 급하게 응급수술을 해야 하는데 보호자가 필요하다고 연락이 온 것이다. 그 여자 분은 바로 나의 어머니였다. 나는 아버지가 일찍 돌아가서서 어머니와 단 둘이 살고 있었고, 어머니의 유일한 보호자는 바로 나였다. 세상에 이런 일이... 나는 
하늘이 무너지는 것 같았다. 아무 생각도 나지 않았다. 눈에서는 눈물만 났고, 다른 생각은 할 수 었었다.

사실 나는 이번 시험을 위해 최선을 다했고, 모두들 이번에 꼭 합격할 수 있을 거라며 나를 응원했다. 그런데... 지금 나는 면접에 갈 수 없는 상황이 된 것이다. 나는 너무 슬펐다.'

\section{2. 화감정과 슬픔감정의 측정}

화를 느끼는 정도를 측정하기 위하여, 소비자가 사전에 점검할 수도 있었던 타인의 잘못이나 부주의로 성취적 접근목적의 달성에 실패했다고 생각하는 정도를 측정하는 문항과 Spielberger, Jacobs, Russell and Crane (1983)의 state-trait anger scale (STAS)에서 화를 느끼는 상태를 측정하는 문항을 이용하여 '나는 실패의 원인이 타인의 잘못에 있었다고 생각 한다' '나는 실패의 원인이 타인의 부주의에 있었다고 생각 한다 '나는 타인의 잘못이나 부주의에 대하여 내가 사전에 점검할 수도 있었다고 생각 한다' '나는 화가 난다' '나는 성질이 난다' '나는 신경질이 난다' '나는 노발대발 한다' '나는 화가 치밀어 옴을 느낀다를 7점 척도(1=전혀 그렇지 않다, $7=$ 매우 그렇다)로 측정하였다.

그리고 환경에 대한 통제력이 없다고 판단하고 통제할 수 없는 환경에 손실이 기인하였다고 생각하여 슬픔을 느끼고(Lazanus, 1991), 또 바람직한 성과의 창출능력이 없다고 믿거나 자신의 행동에 환경이 우호적으로 작용하지 않는다고 믿는 소비자에게 회피동기가 유발된다(Duhachek, Agrawal, \& Han, 2012)는 기존의 연구를 참고하여, 슬픔을 느끼는 정도를 측정하였다. '나는 실패의 원인이 타인의 잘못 보다 예측할 수 없는 상황에 있었다고 생각 한다' '나는 실패의 원인이 부정적으로 작용하는 환경에 있었다고 생각 한다' '나의 목적달성에 부정적으로 작용한 환경에 대하여 내가 사전에 점검할 수 없었다고 생각 한다' '나는 슬픔을 느낀다' '나는 의지할 데가 없음을 느낀다' '나는 기대할 것이 없음을 느낀다' '나는 나를 좋게 할 만한 것이 없음을 느낀다' '나는 슬픔이 나를 탈진시킴을 느낀다'를 7 점 척도로 측정하였다.

\section{3. 회피동기와 접근 동기의 측정}

회피동기의 측정에 Carver and White(1994)의 behavioral inhibition system(BIS)의 문항을 사용하여, '나는 지금 의지할 곳이 없다고 생각되어 내가 실수할까봐 걱정 된다(v1)' '나는 불쾌한 일이 발생할 것 같다고 생각하여, 상당히 동요 된다(V2)' '내가 무엇인가를 잘못할까봐 걱정 된다(v3)' '나의 친구와 비교하여 나는 지금 두려움을 더 느끼는 편이다(V4) '나에 대한 타인의 비판이나 꾸짖음에 상당히 마음이 상할 것 같다(V5)' '타인이 나에게 내는 화에 직면하면 나는 격앙되고 근심 한다(vo' '어떤 나쁜 일이 나에게 발생할 것 같다는 생각에 나는 신경질이 나고 공포감을 느낀다(v7)' 의 문항을 이용한다.

그리고 접근동기의 측정에는 Carver and White(1994)의 behavioral activation system(BAS)의 문항을 참고하여 '원하는 것이 있을 때, 그것을 얻기 위해 전력을 다 할 것이다(p1)' '나는 원하는 것을 얻기 위해 나만의 길을 갈 것이다(p2) '원하는 것을 얻을 수 있는 기회가 있을 때, 나는 곧바로 행동할 것이다(p3)' '원하는 것을 추구할 때, 나는 머뭇거리지 않고 접근할 것이다(p4)' 다른 이유 없이 그 일이 재미있을 것 같다는 이유로 나는 그 일을 수행할 것 같다(p5)' '나는 새로운 감각과 흥분됨을 추구한다(po' '나는 새로운 것이 재미있을 것 같다고 생각되면, 그 새로운 것을 시도할 것이다(p7)' '나는 순간의 매력을 느끼고 행동할 것 같다(p8)의 문항을 7점 척도로 측정한다.

\section{4. 극복전략의 측정}

이 연구에서 극복전략을 문제에 초점을 둔 극복전략과 감정에 초점을 둔 극복전략으로 구분하고. Duhachek, Agrawal, and Han (2012)의 연구에서 사용된 설문문항을 참고하여, 문제에 초점을 둔 극복전략은 '나는 문제를 해결할 수 있는 방법을 찾는다(c1)' '나는 문제를 해결할 수 있는 행동계획을 수립 한다(C2) '나는 해결이 가능한 해법을 찾는다(C3)' '나는 문제를 해결하기 위해 무엇인가를 하려는 노력을 한다(C4)를 7 점 척도로 측정한다. 그리고 감정에 초점을 둔 극복전략은 '나는 내가 지금 느끼는 감정을 인지하고 있다(a1)' '내가 지금 느끼는 감정은 타당하고 정당하다(a2)' '나는 지금 나의 실패의 원인을 알아차리고 내가 느끼는 감정에 빠져 들었다(a3)' '나는 내가 느끼는 감정을 밖으로 날려 보내고 싶다((24)' '나는 나의 감정을 통제하려고 한다(a5)'를 7점 척도로 측정한다.

\section{5. 연구의 설계와 자료수집}

실증을 위하여 조사집단을 화를 느끼는 집단(A 집단)과 슬픔을 느끼는 집단(B 집단)으로 구분하여 설계하고, 설문지의 오류를 탐색하고 수정하기 위하여 사전조사를 실시하였다. 사전조사에 마케팅 관련 과목을 수강하는 대학생 10 명을 선발하여 각 집단에 5 명씩 배정하고 설문지에 응답을 하면서 오타와 설문의 이해에서 난이도를 점검하고, 설문지를 수정하였다.

본 조사에서 마케팅관련과목을 수강하는 클래스의 학부생 80 명에게 화유도설문지 40 부와 슬픔유도 설문지 40 부를 무작위로 배포하였다. 사전에 설문조사 후에 문화상품권이 추첨됨을 고지하고, 설문 후에 문화상품권을 추첨하여 증정하였다. 설문지를 회수하고, 면밀히 검토하고, 80 설문 자료가 가설의 검증에 이용되었다. 


\section{4. 기초분석과 가설의 검증}

\section{1. 기초분석}

Table 1: Principal Component Analysis Results

\begin{tabular}{|c|c|c|c|c|c|c|}
\hline \multirow{2}{*}{ Constructs } & \multirow{2}{*}{ Items } & \multicolumn{4}{|c|}{ Components } & \multirow{2}{*}{$\alpha$} \\
\hline & & 1 & 2 & 3 & 4 & \\
\hline \multirow{8}{*}{$\begin{array}{l}\text { Approach } \\
\text { motive }\end{array}$} & p5 & .883 & -.057 & -.196 & .106 & \multirow{8}{*}{95} \\
\hline & p6 & .882 & -.064 & -.124 & .189 & \\
\hline & p7 & .878 & -.149 & -.230 & .183 & \\
\hline & $\mathrm{p} 8$ & .857 & -.033 & -.222 & .126 & \\
\hline & p4 & .755 & -.315 & -.005 & .360 & \\
\hline & p2 & .752 & -.321 & -.050 & .354 & \\
\hline & $\mathrm{p} 1$ & .749 & -.296 & -.049 & .302 & \\
\hline & p3 & .693 & -.381 & .010 & .348 & \\
\hline \multirow{7}{*}{$\begin{array}{l}\text { Avoidance } \\
\text { motive }\end{array}$} & v7 & -.137 & .866 & .060 & -.140 & \multirow{7}{*}{.92} \\
\hline & v5 & -.148 & .820 & .108 & -.096 & \\
\hline & v4 & -.176 & .813 & .037 & -.092 & \\
\hline & v2 & -.220 & .800 & .182 & -.201 & \\
\hline & v3 & -.237 & .780 & .193 & -.144 & \\
\hline & $\mathrm{v} 1$ & -.117 & .724 & .308 & -.209 & \\
\hline & v6 & -.021 & .712 & .421 & -.012 & \\
\hline \multirow{5}{*}{$\begin{array}{c}\text { Affect } \\
\text { focus } \\
\text { strategy }\end{array}$} & a2 & -.059 & .019 & .810 & -.294 & \multirow{5}{*}{.83} \\
\hline & a1 & -.128 & .170 & .784 & -.263 & \\
\hline & $\mathrm{a} 4$ & -.219 & .279 & .740 & .023 & \\
\hline & a3 & -.144 & .296 & .735 & .016 & \\
\hline & a5 & -.071 & .102 & .613 & .273 & \\
\hline \multirow{4}{*}{$\begin{array}{l}\text { Problem } \\
\text { focus } \\
\text { strategy }\end{array}$} & c1 & .381 & -.243 & -.090 & .799 & \multirow{4}{*}{.94} \\
\hline & c4 & .448 & -.204 & -.032 & .752 & \\
\hline & c2 & .519 & -.224 & -.033 & .750 & \\
\hline & c3 & .533 & -.204 & -.126 & .671 & \\
\hline \multicolumn{2}{|c|}{ eigenvalue } & 6.424 & 5.225 & 3.281 & 3.154 & \\
\hline \multicolumn{2}{|c|}{ variance \% } & 26.766 & 21.772 & 13.671 & 13.144 & \\
\hline
\end{tabular}

응답자의 술응답에서 주의정도 $(\alpha=.908)$ 가 두 실험집단 간에 차이가 없음을 식별하였다 $\left(M_{A}=5.8667, \quad M_{B}=6.0917, t=1225, p>05\right)$. 그리고 화집단(A)에서 화를 느낀 정도 $(\alpha=.839) \quad(M=5.475)$ 가 4 보다 크게
나타났고 ( $t=9.922, p<.01)$, 슬픔집단(B)에서 슬픔을 느낀 정도 $(\alpha=.782)$ $(\mathrm{M}=5.8719)$ 도 4 보다 크게 나타나 $(\mathrm{t}=14.923, \mathrm{p}<.01)$, 집단의 조작의 유의함을 식별하였다. 접근동기, 회피동기와 문제초점극복과 감정초점극복에 대한 측정항목들을 베리멕스 (varimax) 회전법으로 탐색적 주성분 분석을 하였는데, 분석의 결과를 Table 1 로 정리하였다. 구성개념들의 측정문항들이 모두 관련 개념에 수렴하였고, 또 신뢰도(reliability) (Cronbach's $\alpha$ )도 모두 .700 이상으로 식별되어 각 구성개념에 대한 측정문항들의 수렴타당성을 확인하였다.

Table 2: Correlation (Squared) Analysis

\begin{tabular}{|c|c|c|c|c|}
\hline AVE & $\begin{array}{c}\text { Approach } \\
\text { motive }\end{array}$ & $\begin{array}{c}\text { Avoid } \\
\text { motive }\end{array}$ & $\begin{array}{c}\text { Affect } \\
\text { Focus } \\
\text { strategy }\end{array}$ & $\begin{array}{c}\text { Problem } \\
\text { Focus } \\
\text { strategy }\end{array}$ \\
\hline $\begin{array}{c}\text { Approach } \\
\text { motive }\end{array}$ & .737 & & & \\
\hline $\begin{array}{c}\text { Avoid } \\
\text { motive }\end{array}$ & $\begin{array}{c}-.485 \\
(.235)\end{array}$ & .654 & & \\
\hline $\begin{array}{c}\text { Affect } \\
\text { Focus } \\
\text { strategy }\end{array}$ & $\begin{array}{c}. .404 \\
(.163)\end{array}$ & $\begin{array}{c}.505 \\
(.255)\end{array}$ & .547 & \\
\hline $\begin{array}{c}\text { Problem } \\
\text { Focus } \\
\text { strategy }\end{array}$ & $\begin{array}{c}.774 \\
(.599)\end{array}$ & $\begin{array}{c}-.490 \\
(.240)\end{array}$ & $\begin{array}{c}-.320 \\
(.102)\end{array}$ & .817 \\
\hline
\end{tabular}

그리고 구성개념 간의 상관관계의 제곱값과 $\mathrm{AVE}$ 간의 크기비교에서 Table 2 에 제시된 바와 같이 대각선의 AVE의 값이 모두 .5 보다 크고 또 구성개념별로 AVE의 값이 상관관계의 제곱값 보다 크게 나타나 개념들 간의 판별 타당성이 있는 것으로 식별되었다.

가설의 검증에서 각 구성개념의 측정항목의 값은 합산평균하여 사용되었다.

\section{2. 가설의 검증}

$\mathrm{Hla}$ (화감정은 회피동기 보다 접근동기를 유도할 것이다)와 $\mathrm{H} 1 \mathrm{~b}$ (슬픔감정은 접근동기 보다 회피동기를 유도할 것이다)를 검증하기 위하여 화감정집단과 슬픔감정집단 각각에 대하여 회피동기와 접근동기 간의 차이를 $\mathrm{t}$-검증하였다.

Table 3: Results of Testing $\mathrm{H} 1 \mathrm{a} \mathrm{H} 1 \mathrm{~b}$

\begin{tabular}{|c|c|c|c|} 
H (group) & $\begin{array}{c}\text { Approach } \\
\text { motive } \\
\text { Mean(S.D) }\end{array}$ & $\begin{array}{c}\text { Avoidance } \\
\text { motive } \\
\text { Mean(S.D) }\end{array}$ & Results \\
\hline H1a (Anger) & $\begin{array}{c}5.2000 \\
(.90750)\end{array}$ & $\begin{array}{c}3.8143 \\
(1.36726)\end{array}$ & $\begin{array}{c}\mathrm{t}=5.087, \\
\mathrm{P}=.000\end{array}$ \\
\hline $\begin{array}{c}\text { H1b } \\
\text { (Sadness) }\end{array}$ & $\begin{array}{c}3.1875 \\
(1.03543)\end{array}$ & $\begin{array}{c}5.4964 \\
(.75799)\end{array}$ & $\begin{array}{c}\mathrm{t}=11.987, \\
\mathrm{P}=.000\end{array}$ \\
\hline
\end{tabular}


Table 3 에서 제시된 바와 같이, 화감정 집단에서 접근동기 $(M=5.2000)$ 가

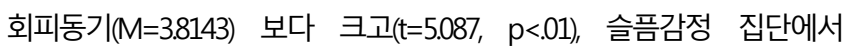
회피동기 $(M=5.4964)$ 가 접근동기 $(M=3.1875)$ 보다 크게 $(t=11.987, p<.01)$ 식별되어, $\mathrm{H} 1 a$ 과 $\mathrm{H} 1 b$ 가 모두 채택되었다.

Table 4: Results of Testing $\mathrm{H} 2 \mathrm{a} \mathrm{H} 2 \mathrm{~b}$

\begin{tabular}{|c|c|c|c|}
\hline$H$ (group) & $\begin{array}{c}\text { Affect } \\
\text { focus } \\
\text { Mean(S.D) }\end{array}$ & $\begin{array}{l}\text { Problem } \\
\text { focus } \\
\text { Mean(S.D) }\end{array}$ & Results \\
\hline H2a(Anger) & $\begin{array}{c}4.7900 \\
(.96498)\end{array}$ & $\begin{array}{c}5.8063 \\
(.94816)\end{array}$ & $\begin{array}{c}\mathrm{t}=4.917 \\
\mathrm{P}=.000\end{array}$ \\
\hline $\mathrm{H} 2 \mathrm{~b}$ (Sadness) & $\begin{array}{c}5.5850 \\
(0.73782)\end{array}$ & $\begin{array}{c}3.9625 \\
(0.89434)\end{array}$ & $\begin{array}{c}t=9.272, \\
P=.000\end{array}$ \\
\hline
\end{tabular}

$\mathrm{H} 2 \mathrm{a}$ (화감정은 감정 보다 문제에 초점을 둔 극복전략을 선택하게 한다)과 $\mathrm{H} 2 \mathrm{~b}$ (슬픔감정은 문제 보다 감정에 초점을 둔 극복전략을 선택하게 한다)를 검증하기 위하여 각각의 감정집단에 대하여 문제에 초점을 둔 극복전략과 감정에 초점을 둔 극복전략 간의 차이를 $\mathrm{t}-$ 검증하였다. Table 4 에서 제시된 바와 같이, 화감정 집단에서 문제초점극복전략 $(M=5.8063)$ 이 감정초점극복전략 $(M=4.7900)$ 보다 크고 $(\mathrm{t}=4.917, \mathrm{p}<.01)$, 슬픔감정 집단에서 감정초점 극복전략 $(\mathrm{M}=5.5850)$ 이 문제초점 극복전략 $(M=3.9625)$ 보다 크게 $(t=9.272, p<.01)$ 식별되어 $\mathrm{H} 2 \mathrm{a}$ 과 $\mathrm{H} 2 \mathrm{~b}$ 도 모두 채택되었다.

\section{5. 연구의 요약과 시사점 및 한계}

\section{1. 연구의 요약}

접근목적의 달성에 실패하는 경우에, 개인이 통제가 가능한 타인의 잘못으로 실패가 발생했다고 판단하여 느끼는 화감정(anger)(Lemer et al, 2015)과 개인이 통제할 수 없는 환경에 의해 실패가 발생했다고 판단하여 느껴는 슬픔감정(sadness) (Lazanus, 1991) 간에 원인주제가 서로 다름을 이 연구는 이론적 고찰을 통해서 간파하였다. 그리고 사전에 느낀 화감정과 슬픔감정 간에 원인주제가 서로 달라서 차후의 의사결정에서 동기가 서로 다를 수 있고, 또 화의 극복전략과 슬픔의 극복전략이 서로 다를 수 있음을 이론적으로 검토하여 가설을 설정하였다.

가설을 검증하기 위해, 개인적으로 중요한 목적의 추구에서 실패하여 화를 느끼는 시나리오와 슬픔을 느끼는 시나리오를 개발하였고, 화감정을 느끼는 집단과 슬픔감정을 느끼는 집단으로 집단간 실험설계를 하였다. 이 연구에서 사용되는 구성개념별 측정문항들을 선행연구를 통하여 탐색하고 화감정 설문지와 슬픔감정 설문지를
개발하였다. 자료의 수집에서 마케팅관련 과목을 수강하는 학부생을 모집단으로 설정하고 화감정설문과 슬픔감정설문에 각각 40 명씩 응답한 자료를 실증분석에 사용하였다. 가설의 검증에 t-검증방법이 이용되었고, 분석의 결과는 다음과 같이 요약된다.

첫째, 화감정은 회피동기 보다 접근동기를 유도할 것이다의 $\mathrm{Hla}$ 와 슬픔감정은 접근동기 보다 회피동기를 유도할 것이다의 $\mathrm{H} 1 b$ 가 채택되었다. 둘째, 화감정은 감정 보다 문제에 초점을 둔 극복전략을 선택하게 한다의 $\mathrm{H} 2 \mathrm{a}$ 와 슬픔감정은 문제 보다 감정에 초점을 둔 극복전략을 선택하게 한다의 $\mathrm{H} 2 \mathrm{~b}$ 도 채택되었다.

\section{2. 연구의 시사점과 한계}

선행연구에서 동기는 행동을 활성화하고 유지시키는 소비자 내부의 모든 변수를 포괄하는 개념으로 사용되는데(Reeve, 2005), 특히 성취동기는 유능함에 접근하고 무능함을 회피하는 동기이다(Thrash \& Hurst, 2008). 따라서 성취동기는 유능함의 달성이나 무능함의 회피를 지향하는 행동을 유도하고 활성화하는 관점으로 파악할 수 있다. 그리고 성취동기에서 접근동기는 행동이 긍정적 성과를 향하여 유도되고 활성화됨을 의미하고, 회피동기는 행동이 부정적인 실패를 회피하기 위하여 유도되고 활성화됨을 의미한다. 그리고 감정은 지각, 평가, 표찰과 같은 인지과정에 영향을 미치며, 감정을 느끼게 한 상황과 관련하여 생리적인 조정을 하게하고, 표현적이고 목적 지향적이며 적응적인 행동을 유도하는, 즉 인지, 생리, 그리고 행동 간의 복합적인 상호작용을 유도한다(Kleinginna \& Kleinginna, 1981). 따라서 동기와 감정은 모두 내부적 상태이고 목적을 지향하는 행동을 유도하고 활성화시키는 역할을 한다는 공통점을 갖고 있다.

그런데 부정적인 기분은 위협을 지각하게 하고 좀 더 경계적이고 체계적인 처리를 하게 하는데, 화와 슬픔 감정은 느끼게 하는 주제원인인 환경 통제성의 지각정도가 서로 달라서 동기와 주의의 초점을 다르게 할 수 있다. 선행연구는 환경에 대한 자신의 통제성 지각에 따라 서로 다르게 느껴지는 화와 슬픔에서 동기의 차이와 주의의 초점차이에 관한 연구가 부족하였다. 이 연구에서 사전에 느낀 화감정은 회피동기 보다 접근동기를 유도하고, 슬픔감정은 접근동기 보다 회피동기를 유도함이 식별되었다. 그리고 그 화감정은 감정 보다 문제의 해결에 초점을 둔 극복전략을 선택하게 하고, 슬픔감정은 문제의 해결 보다 감정에 초점을 두고 감정 자체를 극복하는 전략을 선택하게 함이 탐색되었다. 따라서 이 연구는 부정감정을 느끼는 경우에 그 감정을 유발한 원인주제에 따라서 차후의 의사결정에서 동기와 극복전략의 차이가 있음을 식별하여 환경적 부정감정의 의사결정의 효과에 관한 이론의 발전에 기여할 수 있다. 
그리고 관리적 시사점을 이 연구는 제시한다. 첫째, 소비자에게 현재상태가 기대수준에 이르지 못하여 기대상태를 충족시키려는 동기가 유발되는데, 환경적 화감정은 접근동기를 유발하고 문제에 초점을 두고 해결하려 한다. 따라서 마케터는, 화감정을 느끼는 소비자에게, 자신의 브랜드를 문제를 해결하는 접근적 표현이 담긴 메시지로 접근할 필요가 있다. 마케터는 화감정을 느낀 소비자에게 자신의 브랜드가 소비자의 성공을 표현할 수 있는 점을 강조하는 메시지로 접근할 필요가 있다. 둘째, 슬픔감정을 느끼는 소비자에게는 자신의 브랜드에는 무엇인가를 잘못할까봐 걱정할 필요가 없고 타인의 비판이나 꾸짖음에서 자신을 정당화할 수 있는 근거를 메시지에 담아 소구할 필요가 있다. 마케터는 슬픔감정을 느낀 소비자에게 자신의 브랜드의 선택이 소비자에게 잘못된 선택일 수 있다는 걱정을 할 필요가 없고 선택의 정당성을 표현할 수 있는 점을 강조하는 메시지로 접근할 필요가 있다.

그런데 이 연구는 이론적 관리적 시사점에도 불구하고 한계점을 갖고 있다. 첫째, 상황이 부정적이며 자존감을 위협하고, 또 타인이 부정적인 사건을 발생하게 한 원인요인으로 지각되어 화감정이 느껴진다는 것은 직관적인 접근일 수 있다. 사전에 소비자 자신이 대처하여 부정적인 사건을 예방할 수 있었다는 사고를 하여 자기 자신을 스스로 나무랄 수도 있다. 이러한 관점을 고려하는 미래의 연구가 요구된다. 둘째, 소비자는 부정적인 결과에서 탈출하려 하고, 고통을 회피하고 기쁨을 추구하는 성향이 있고(Higgins, 1997), 부정감정을 느끼게 한 집단에서 이탈성향을 보일 수 있다(Choi, 2019). 그런데 이 연구에 집단에 대한 슬픔감정의 이탈성향효과를 고려하지 못했다. 셋째, 의사결정에서 소비자는 머리(이성)와 가슴(감정) 간의 딜레마에 직면할 수 있다. 여기서 보통 소비자는 이성적 사고의 틀(lay rationalism)에 의해 이성을 따르는 성향이 있다(Hsee, Zhang, Yu, \& Xi, 2003; Choi, Wang, \& Chen, 2018; Choi, Cai, $\&$ Li, 2019). 이 연구에서 이러한 틀의 관점에서 조절효과를 검토하지 못하였다.

\section{References}

Ambady, N., Gray, H. M. (2002). On being sad and mistaken: Mood effects on the accuracy of thin-slice judgments. Journal of Personality and Social Psychology, 83, 947-961

American Psychiatric Association (2000). Diagnostic and statistical manual of mental disorders (4th ed., Text Revision). Washington, DC: American Psychiatric Association.

Atalay, A. S., \& Meloy, M. G. (2011). Retail therapy: A strategic effort to improve mood. Psychology \& Marketing, 28(6), 638659.

Bandura, A. (1977). Self-efficacy: toward a unifying theory of behavioral change. Psychological review, 84(2), 191-215.

Blanchard, D. C., \& Blanchard, R. J. (1984). Affect and aggression: An animal model applied to human behavior. Advances in the Study of Aggression, 1, 1-62.

Bodenhausen, G. V., Gabriel, S., \& Lineberger, M. (2000). Sadness and susceptibility to judgmental bias: The case of anchoring. Psychological Science, 11, 320-323

Carver, C. S. (2001). Affect and the functional bases of behavior: On the dimensional structure of affective experience. Personality and Social Psychology Review, 5(4), 345-356.

Carver, C. S. (2008). Two distinct bases of inhibition of behaviour: Viewing biological phenomena through the lens of psychological theory. European Journal of Personality, 22(5), 388-390.

Carver, C. S., \& Scheier, M. F. (1998). On the self-regulation of behavior. Cambridge, England: Cambridge University Press.

Carver, C. S., \& White, T. L. (1994). Behavioral inhibition, behavioral activation, and affective responses to impending reward and punishment: The bis/bas scales. Journal of Personality and Social Psychology, 67(4), 319-333.

Choi, N.-H. (2019). Social identity threat and across-domain compensatory consumption intention. International Journal of Industrial Distribution \& Business, 10(11), 35-47.

Choi, N.-H., Cai, Y., \& Li, Z. (2019). Effects of lay rationalism, attitude dimension and involvement type on intent to purchase hedonic product. Journal of Distribution Science, 17(8), 45-56.

Choi, N.-H., Wang, 1., \& Chen, C. (2018). Interaction effects of lay theories and failure type on adaptive versus compensatory consumption behavior. International Journal of Industrial Distribution \& Business, 9(7), 19-32.

Clore, G. L., Wyer, R. S. Jr., Dienes, B., Gasper, K., \& Gohm, C., Isbell, L. (2001). Affective feelings as feedback: Some cognitive consequences. In L. L. Martin \& G. L. Clore (Eds.), Theories of Mood and Cognition: A User's Guidebook (pp. 2762). Mahwah, NJ: Erlbaum.

Cornil, Y., \& Chandon, P. (2013). From fan to fat? Vicarious losing increases unhealthy eating, but self-affirmation is an effective remedy. Psychological Science, 24(10), 1936-1946.

Diener, E., \& Lucas, R. E. (2000). Subjective emotional wellbeing. In M. Lewis \& J. M. Havialand-Jones (Eds.), Handbook of Emotions (2nd ed., pp. 325-337). New York, NY: Guilford Press.

Diener, E. (1984). Subjective well-being. Psychological bulletin, 95(3), 542-575.

Duhachek, A., Agrawal, N., \& Han, D. (2012). Guilt versus shame: coping, fluency, and framing in the effectiveness of responsible drinking messages. Journal of Marketing Research, 49(6), 928-941.

Duhachek, A., \& Iacobucci, D. (2005). Consumer personality and coping: Testing rival theories of process. Journal of Consumer Psychology, 15(1), 52-63.

Elliot, A. J. (2008). Approach and avoidance motivation. In A. J. Elliot (ed.), Handbook of approach and avoidance motivation (pp. 3-16). New York, NY: Psychology Press.

Han, S., Lerner, J. S., \& Keltner, D. (2007). Feelings and consumer decision making: The appraisal-tendency framework. Journal of Consumer. Psychology, 17, 158-168

Higgins, E. T. (1997). Beyond pleasure and pain. American psychologist, 52(12), 1280-1300.

Higgins, E. T. (2000). Making a good decision: value from fit. American psychologist, 55(11), 1217-1230. 
Hsee, C. K., Zhang, J., Yu, F., \& Xi, Y. (2003). Lay rationalism and inconsistency between predicted experience and decision. Journal of Behavioral Decision Making, 16(4), 257-272.

Idson, L. C., Liberman, N., \& Higgins, E. T. (2000). Distinguishing gains from nonlosses and losses from nongains: A regulatory focus perspective on hedonic intensity. Journal of Experimental Social psychology, 36(3), 252-274.

Kleinginna, P., \& Kleinginna, A. (1981). A categorized list emotion definitions, with suggestion for a consensual definition. Motivation and Emoltion, 5, 263-291.

Lang, P. J. (1995). The emotion probe: studies of motivation and attention. American Psychologist, 50(5), 372.

Lazarus, R. S. (1991). Emotion and adoption. New York, NY: Oxford University Press.

Lazarus, R. S., \& Folkman, S. (1984). Stress, appraisal, and coping. New York, NY: Springer Publishing.

Lerner, J. S., \& Keltner, D. (2000). Beyond valence: toward a model of emotion-specific influences on judgement and choice. Cognition and Emotion. 14, 473-493

Lerner, J. S., \& Keltner, D. (2001). Fear, anger, and risk. Journal of Personality and Social Psychology, 81(1), 146-159.

Lerner, J. S., Li, Y., Valdesolo, P., \& Kassam, K. S. (2015). Emotion and decision making. Annual Review of Psychology, 66, 799-823.

Lerner, J. S., Small, D. A., \& Loewenstein, G. (2004). Heart strings and purse strings carryover effects of emotion on economic decisions. Psychological Science, 15(5), 337-341.

Lewis, M. (1993). The development of anger and rage. In R. A. Glick \& S. P. Roose (Eds.) Rage, power, and aggression, (pp. 148-168). New Haven, CT: Yale University Press.

Lisjak, M., Bonezzi, A., Kim, S., \& Rucker, D. D. (2015). Perils of compensatory consumption: Within-domain compensation undermines subsequent self-regulation. Journal of Consumer Research, 41(5), 1186-1203.

Oettingen, G., \& Gollwitzer, P. M. (2004). Goal Setting and Goal Striving. In M. B. Brewer \& M. Hewstone (Eds.), Emotion and motivation(pp.165-183). Malden, MA: Blackwell Publishing

Plutchik, R. (1980). Emotion a psychoevolutionary synthesis. New York, NY: Harper and Row.

Reeve, J. (2005). Understanding motivation and emotion (4th ed.). Hoboken, NJ: Wiley.
Rolls, E. T. (2000). The brain and emotion. Oxford, England: Oxford University Press.

Roseman, I. J. (1991). Appraisal determinants of discrete emotions. Cognition \& Emotion, 5(3), 161-200.

Roseman, I. J., Wiest, C., \& Swartz, T. S. (1994). Phenomenology, behaviors, and goals differentiate discrete emotions. Journal of Personality and Social Psychology, 67(2), 206-221.

Ryan, R. M., \& Deci, E. L. (2001). On happiness and human potentials: A review of research on hedonic and eudaimonic well-being. Annual review of psychology, 52(1), 141-166.

Spielberger, C. D., Jacobs, G. H., Russell, S. F., \& Crane, R. S. (1983). Assesment of anger: The state-trait anger scale. In J. N. Butcher \& C. D. Spielberger (Eds), Advances in Personality Assesment (Vol. 2, pp. 159-187). Hillsdale, NJ: Lawrence Erlbaum Associates.

Schwarz, N. (1990). Feelings as information: Informational and motivational functions of affective states. In E. T. Higgins \& R M. Sorrentino (Eds.), Handbook of Motivation and Cognition: Foundations of Social Behavior (Vol. 2, pp. 527-561). New York, NY: Guilford.

Sujan, M., Sujan, H., Bettman, J. R., \& Verhallen, T. (1999). Sources of consumers' stress and their coping strategies. Proceedings of European Advances in Consumer Research. 4, 182-187.

Tamir, M., \& Robinson, M. D. (2007). The happy spotlight: Positive mood and selective attention to rewarding information. Personality and Social Psychology Bulletin, 33(8), 1124-1136.

Thrash, T. M., \& Hurst, A. L. (2008). Approach and avoidance motivation in the achievement domain: Integrating the achievement motive and achievement goal traditions. In A. J. Elliot (ed.), Handbook of approach and avoidance motivation (pp. 217-233). New York, NY: Psychology Press.

Tomkins, S. S. (1978). Script theory: Differential magnification of affects. In Nebraska symposium on motivation. Lincoln, NE: University of Nebraska Press.

Updegraff, J. A., Gable, S. L., \& Taylor, S. E. (2004). What makes experiences satisfying? The interaction of approach-avoidance motivations and emotions in well-being. Journal of Personality and Social Psychology, 86(3), 496-504. 